\title{
Risk of Mental Disorders in Children and Adolescents With Atopic Dermatitis: A Systematic Review and Meta-Analysis
}

\author{
Qian-Wen Xie', Xiaolu Dai ${ }^{2}$, Xinfeng Tang ${ }^{1}$, Celia H. Y. Chan ${ }^{1}$ and Cecilia L. W. Chan ${ }^{1 *}$ \\ 'Department of Social Work and Social Administration, The University of Hong Kong, Pokfulam, Hong Kong, ${ }^{2}$ Department \\ of Social Work and Social Administration, Changsha Social Work College, Changsha, China
}

\section{OPEN ACCESS}

Edited by:

Gianluca Castelnuovo,

Catholic University of the Sacred

Heart, Italy

Reviewed by:

Steven Richard Feldman, Wake Forest School of Medicine,

United States

Ava Schulz,

University of Zurich, Switzerland

*Correspondence:

Cecilia L. W. Chan cecichan@hku.hk

Specialty section:

This article was submitted to Psychology for Clinical Settings, a section of the journal

Frontiers in Psychology

Received: 27 April 2019

Accepted: 16 July 2019

Published: 06 August 2019

Citation:

Xie Q-W, Dai X, Tang X, Chan CHY and Chan CLW (2019) Risk of Mental Disorders in Children and Adolescents With Atopic Dermatitis: A Systematic Review and Meta-Analysis.

Front. Psychol. 10:1773. doi: 10.3389/fpsyg.2019.01773
Assessing the psychological effects on children and adolescents of suffering atopic dermatitis (AD) is essential, when planning successful management. This study aimed to systematically review the literature regarding risk of mental disorders in children and adolescents with, or without, AD; and to explore confounders. We identified potentially relevant studies from EMBASE, MEDLINE, PsycINFO, ERIC, the British Nursing Index, the Family and Society Studies Worldwide, the Social Work Abstracts, and the Sociological Abstracts from inception to Sep 30, 2018. Investigators independently screened titles and abstracts, and then full-texts. Investigators independently extracted data from included studies. Meta-analyses using random-effects models were performed, reporting odds ratios (ORs; 95\% Cls). Thirty-seven studies ( $n=2,068,911$ children/ adolescents) were included. Meta-analysis of 35 studies found that children and adolescents with $A D$ had significantly higher risk of total mental disorders than those without $\mathrm{AD}(\mathrm{OR}=1.652 ; 95 \% \mathrm{Cl}, 1.463-1.864)$. There was no significant difference in risks for $\mathrm{ADHD}(\mathrm{OR}=1.563$; 95\% $\mathrm{Cl}, 1.382-1.769)$; sleep disorders $(\mathrm{OR}=2.100 ; 95 \%$ $\mathrm{Cl}, 1.322-3.336)$; anxiety (OR = 1.339; 95\% Cl, 1.062-1.687); depression (OR $=1.402$ $95 \% \mathrm{Cl}, 1.256-1.565)$; conduct disorder (OR = $1.49495 \% \mathrm{Cl}, 1.230-1.815)$; or ASD $\left(\mathrm{OR}=2.574 ; 95 \% \mathrm{Cl}, 1.469-4.510 ; Q_{b}=8.344, p=0.138\right)$. Race/ethnicity of child, target of comparison, type of studies, representativeness of the sample, measures of $A D$ and mental disorders were significant moderators for total mental disorders. Integrated, holistic, multidisciplinary management of pediatric $A D$ is significantly important, which emphasizes the well-being of the whole person.

Keywords: pediatric atopic dermatitis, children and adolescents, mental disorders, eczema, integrative medicine

\section{INTRODUCTION}

Atopic dermatitis $(\mathrm{AD})$ is the most common skin diseases in the pediatric population that affects about $15-30 \%$ children and adolescents worldwide (Archer, 2013). AD mostly occurs in early childhood, which is a critical period of life for physical and psychological development (Bronkhorst et al., 2016). The complex pathogenesis of $\mathrm{AD}$ may underpin the lack of effective medical treatment for many cases, with one-third of affected children continuing to experience symptoms in adolescence (Mitchell et al., 2015).

The link between pediatric $\mathrm{AD}$ and mental disorders, especially attention-deficit/hyperactivity disorder (ADHD), has attracted increasing attention in the past decade, due to parallel rises in 
their global prevalence (Nygaard et al., 2016). Also, mental disorders and skin diseases are in the top 20 conditions with the highest personal healthcare costs for children and adolescents in some developed countries such as the United States (Bui et al., 2017). It is becoming more apparent that healthcare professionals should understand the psychological effects on children of suffering $\mathrm{AD}$ in order to treat it successfully (Dertlioglu et al., 2012).

However, the overall trends of mental disorders in children with $\mathrm{AD}$ are not clear. Important knowledge gaps exist in the area of research. There are inconsistent findings regarding the risk of mental disorders in children with $\mathrm{AD}$ (Cheng et al., 2015; Lee et al., 2016). Most previous research has focused on associations between pediatric $\mathrm{AD}$ and one mental disorder only generally ADHD (Horev et al., 2017; Schans et al., 2017). A recent systematic review found the positive association between pediatric $\mathrm{AD}$ and depression (Rønnstad et al., 2018). However, it did not assess the risk of other important types of mental disorders in children with eczema such as anxiety, autism spectrum disorder (ASD), and conduct disorder, etc. Some relevant studies may be not included in this review since it only searched three medical databases. Moreover, no study to date has compared the risks of different types of mental disorders in children with AD. Additionally, previous research has suggested that $\mathrm{AD}$ prevalence is associated with demographic factors such as age, gender (Carson, 2013), race/ethnicity (Silverberg and Paller, 2015); socioeconomic factors such as family socioeconomic status (SES) (Mercer et al., 2004), and country SES (Stewart et al., 2001). Yet, no study has attempted to explore the impact of these potential confounders on the association between pediatric AD and mental disorders. Understanding different circumstances and contexts is essential when planning holistic health care for children suffering AD.

Therefore, this paper describes the findings of a systematic literature review and meta-analysis. Its objectives were to: (1) systematically review the available evidence and assess whether children and adolescents with $\mathrm{AD}$ have higher risks of mental disorders than children who do not suffer from AD; (2) determine risks of specific mental disorders for children suffering $\mathrm{AD}$; and (3) analyze the effect of potential confounders by seeking differences in effect sizes related to participant and study characteristics.

\section{MATERIALS AND METHODS}

\section{Protocol and Registration}

The study followed the systematic review protocol PROSPERO 2018: CRD42018087957 (Xie and Tang, 2018). Findings were reported using the Preferred Reporting Items for Systematic Reviews and Meta-Analyses diagnostic test accuracy (PRISMADTA) guideline (McInnes et al., 2018).

\section{Eligibility Criteria}

English-language published, peer-reviewed scientific articles reporting primary experimental or observational studies were potentially eligible for inclusion. Studies should: (1) target children and adolescents ( $\leq 18$ years old); (2) assess mental disorders categorized by the Diagnostic and Statistical Manual of Mental Disorders Fifth Edition (DSM-5; American Psychiatric Association, 2013) or outcome domains identified as "mental health problems" or "psychiatric disorders," etc.; (3) compare the prevalence and/or incidence of mental disorders between children or adolescents with AD, and those without AD; and (4) apply quantitative research methods and report effect sizes, or data that could be extracted to compute effect sizes. Excluded were conference abstracts, secondary evidence or case reports.

\section{Information Sources}

A systematic search of eight electronic databases was undertaken in September 2018, including EMBASE (from 1974), MEDLINE (from 1946), PsycINFO (from 1806), ERIC (from 1966), Social Work Abstracts (from 1968), Family and Society Studies Worldwide (from 1970), British Nursing Index (from 1994), and Sociological Abstracts (from 1952). The authors believed that these databases were most likely to contain papers appropriate to this review.

\section{Search}

Three groups of search terms were used in combination and modified according to the requirements of the electronic databases: (1) AD (eczema OR atopic dermatitis OR atopic eczema OR neurodermatitis); (2) children (child* OR boys OR girls OR juvenil* OR minors OR adolesc* OR preadolesc* OR pre-adolesc* OR pre-school OR preschool OR pediatric* OR pediatric* OR pubescen* OR puberty OR school* OR campus OR teen* OR young OR youth*); and (3) mental disorders (psychiatri* OR psycho* OR mental OR depress* OR anxiet* OR disorder* OR therap* OR counsel* ${ }^{*}$ ). Search dates were from database inception to Dec 6, 2017. A final prepublication search of these databases was undertaken from Oct 1, 2017 to Sep 30, 2018. The reference lists of previous systematic reviews were hand-searched (Chida et al., 2008; Schmitt et al., 2010b; Schans et al., 2017; Rønnstad et al., 2018). All records were incorporated into this study.

\section{Study Selection}

All records were exported into EndNote software (EndNote, RRID:SCR_014001). Two investigators (Q-WX and XT) independently screened titles and abstracts for eligibility, and two investigators (Q-WX and XD) independently assessed full texts of potentially relevant studies. Differences were resolved by discussing with a third investigator.

\section{Data Collection Process}

Information on participant and study characteristics was independently extracted by two investigators (Q-WX and XD) by using a pre-piloted, standardized coding scheme (Table 1), demonstrating a high level of inter-rater agreement (mean Cohen's Kappa $=0.90)$.

\section{Risk of Bias, and Applicability}

Two investigators (Q-WX and XD) independently assessed the methodological quality of each study using the Newcastle-Ottawa 
TABLE 1 | Coding scheme.

\begin{tabular}{|c|c|c|}
\hline No. & Variable & Definitions and Conditions \\
\hline A & Sample size & Numbers of participants in AD group/Non-AD group \\
\hline$B$ & Age of child (mean) & Mean age (years) of participated children in total sample \\
\hline C & Age of child (range) & Range of age of participated children in total sample \\
\hline D & Sex of child & Percentage of females in total sample \\
\hline E & Race/ethnicity of child & Percentage of racial or ethnic minorities in total sample \\
\hline $\mathrm{F}$ & Asthma & Percentage of children who were identified as having asthma by the included study in AD group/Non-AD group \\
\hline G & Home SES & Percentage of families which were defined as low SES by the included study in total sample \\
\hline $\mathrm{H}$ & Location & Country or territory in which the study was conducted \\
\hline I & Type of study & 1 = cohort, 2 = case-control, 3 = cross sectional \\
\hline$J$ & Representativeness of the sample & 1 = convenience sample or clinical sample, 2 = random sample or community sample \\
\hline K & Target of comparison & Nature of the Non-AD group ( 1 = healthy control, 2 = general population, 3 = people with other conditions) \\
\hline L & Equivalence & Equivalence of AD group and Non-AD group (1 = yes, 2 = no) \\
\hline M & Assessment of $A D$ & $\begin{array}{l}\text { Method employed to identify AD of participants }(1=\text { diagnosed by a doctor or professional, } 2=\text { self/parental report of } \\
\text { doctoral diagnosis, } 3=\text { questionnaire) }\end{array}$ \\
\hline $\mathrm{N}$ & Assessment of quality & Total score calculated according to the Newcastle-Ottawa Quality Assessment Forms \\
\hline $\mathrm{O}$ & Outcome domains & Type of mental disorders of participated children identified by the included study \\
\hline $\mathrm{P}$ & Measurement of outcome & Name of scales or other methods used to measure the mental disorders of participated children \\
\hline Q & Rater of outcomes & People who rate the mental disorders of participated children ( $1=$ child/adolescent, $2=$ parent/caregiver, $3=$ clinician $)$ \\
\hline $\mathrm{R}$ & Original metric & Original data used to calculate effect sizes ( 1 = OR, 2 = mean and SD, 3 = rates or events) \\
\hline
\end{tabular}

Data of follow-up tests in cohort study; AD, Atopic dermatitis; OR, odds ratio; SD, standard deviation; SES, socioeconomic status.

Scale (NOS) for case-control and cohort studies (Wells et al., 2012), and cross-sectional studies (Herzog et al., 2013). The NOS assess three domains of quality for each included study, including the selection of sample, the section of comparability, and exposure or outcome. The highest score was 9 for a study when it satisfied all criteria.

\section{Synthesis of Results and Meta-Analysis}

All calculations were performed using Comprehensive MetaAnalysis (CMA, RRID:SCR_012779) software and applying the random-effects models given the heterogeneity of the included studies (Lipsey and Wilson, 2001). A meta-analysis was performed to calculate an overall effect size of all studies combined, to illustrate the risk of Total Mental Disorders in children with $\mathrm{AD}$, compared to those without $\mathrm{AD}$. To do this, effect size ORs were first computed for each study. When one type of mental disorder was measured by multiple tests, findings were combined by averaging the effect sizes within that study. When a study contained more than one outcome domain, effect sizes of different outcome domains were aggregated by averaging means to generate a combined effect size. This avoided the risk of including more than one effect size per construct per sample (Lipsey and Wilson, 2001; Borenstein et al., 2009). Independent meta-analyses were performed, and subtotal effect sizes of relevant studies were combined to illustrate the risks of specific types of mental disorders (e.g., ADHD, sleep disorders, anxiety, depression, etc.) in children with $\mathrm{AD}$, compared to those without $\mathrm{AD}$. Crude odds ratios (ORs) were used to compare the relative likelihood of the occurrence of mental disorders, given exposure to AD. Precision of effect sizes was reported by $95 \%$ Confidence Intervals (CIs). A combined effect size was considered significant if the CI did not include 1 and the $p$-value was significant in the $Z$-test.

\section{Additional Analyses \\ Assessment of Heterogeneity}

Heterogeneity across studies was computed using the Q statistic and quantified by the I-squared $\left(I^{2}\right)$ value (Borenstein et al., 2009).

\section{Sensitivity Analyses}

We performed sensitivity analyses by removing studies one-byone to estimate the strength of association between pediatric $\mathrm{AD}$ and mental disorders.

\section{Assessment of Publication Bias}

Omitting unpublished studies from this meta-analysis could bias the estimates of risk of mental disorders in children with $\mathrm{AD}$, because studies with significant findings might have more opportunities to be published in peer-reviewed journals than studies with Non-significant findings. Possible publication bias was tested using funnel plot asymmetry (Borenstein et al., 2009) and quantified by the Egger's test (Sterne et al., 2001). The unbiased effect size was calculated using the trim and fill approach. The Rosenthal's fail-safe number was applied to indicate the number of potentially missing studies with Nonsignificant results, that would have to be included in the metaanalysis before the $p$-value became Non-significant.

\section{Subgroup Analysis}

Each type of mental disorder was treated independently. Each outcome domain was also treated as an independent correlate, by comparing effect sizes for different types of mental disorders in children with $\mathrm{AD}$, compared to those without $\mathrm{AD}$. 


\section{Meta-Regression Analysis and Moderator Analysis}

By using mixed effects models, the effect of potential confounders (moderators) were explored to explain the variability in effect sizes of Total Mental Disorder if the assumption of homogeneity between studies was rejected. Moderator analysis was conducted for categorical variables by comparing effect sizes for studies grouped by study classification, on the potential moderator.

\section{RESULTS}

\section{Study Selection}

The electronic database search identified 5,788 records. Handsearching reference lists of earlier systematic reviews yielded six additional relevant studies. After de-duplication, 3,452 studies remained for title and/or abstract screening, following which 3,207 studies were excluded as not being relevant. Further excluded were 200 studies after the full-texts of 245 potentially eligible studies had been reviewed. Thirty-seven studies were selected after full-text screening. Two papers only provided adjusted hazard ratios (HRs) from which effect sizes could not be determined (Cheng et al., 2015; Riis et al., 2016). Sensitivity analyses (conducted by removing papers one at a time) indicated no significant change of the overall results. Therefore, thirtyfive studies were included in the current meta-analysis. Figure 1 outlines the process of study selection.

\section{Study Characteristics}

Table 2 presents characteristics of participants and studies. Outcomes and measures are reported in Table 3.

\section{Characteristics of Participants}

Data from 1,935,147 children and adolescents (521,976 identified as having $\mathrm{AD}$ ) were included in this systematic review. Study sample size ranged from $n=30$ to $n=774,524$. Participants' mean age was 9.12 years $(S D=3.29$ years, $k=23)$. Similar numbers of boys and girls were reported (Mean $\%$ of females $=48.5 \%, k=32$ ). Three-quarters of subjects were Non-Caucasian $(M=73.6 \%$, $k=13$ ), and 10 studies were conducted totally on Asian populations $(n=1,089,330)$. AD diagnosis of children was confirmed by a doctor or other healthcare professional in most studies $(k=19)$. More than $20 \%$ of children with AD were also reported as having asthma $(M=22.7 \%, k=8$; compared with $7.8 \%$ in the Non-AD group. More than $20 \%$ of participating families were from low SES circumstances $(M=21.5 \%, k=17)$. The majority of participants $(k=29, n=1,933,466)$ were recruited from developed countries or territories with high Human Development Index (HDI) scores (8.00 or more; United Nations Development Programme [UNDP], 2018).

\section{Characteristics of Studies}

Eleven studies were published in 2010 or earlier. All studies applied observational study designs including 11 cohort studies, 12 case control studies, and 12 cross-sectional studies. In terms of representativeness of sample, 22 studies used a random sample or a community sample. Nineteen studies compared the prevalence or incidence of mental disorders in children with $\mathrm{AD}$ to the general population, rather than healthy controls.

\section{Outcomes and Measures}

Thirteen types of mental disorders were reported in the papers included in this systematic review including: ADHD $(n=1,414,406)$, sleep disorders $(n=82,051)$, anxiety $(n=3,881)$, depression $(n=449,591)$, conduct disorder $(n=94,091)$, autism spectrum disorder (ASD; $n=890,966$ ), affective disorder $(n=3,429)$, eating disorder $(n=3,026)$, oppositional defiant disorder (ODD; $n=711)$, attachments disorder $(n=154)$, pervasive developmental disorder (PDD; $n=557$ ), personality disorders $(n=2,872)$, speech disorder $(n=336,763)$, and tic disorders $(n=154)$. Mental disorders of children were diagnosed by clinicians or reported by parents/caregivers or children/adolescents.

\section{Risk of Bias and Applicability}

The NOS total scores per-study ranged from 3 to 9 (N column in Table 2). Twenty-five studies had high methodological quality (NOS score of 7 or higher), whilst 10 studies had moderate quality (NOS score 3-6). The component NOS scores are reported in Supplementary Appendix 1.

\section{Meta-Analysis}

Children and adolescents with AD had an overall statistically significant increased risk of total mental disorders compared with those without $\mathrm{AD}(\mathrm{OR}=1.652 ; 95 \% \mathrm{CI}, 1.463-1.864$; $Z=8.112, p<0.001)$. The assumption of homogeneity was rejected $(Q=454.874, p=0.000)$, as approximately $93 \%$ total variance among studies was due to heterogeneity $\left(I^{2}=92.53 \%\right)$. See Figure 2 for a summary of individual study effects and summary effects and the heterogeneity.

More specifically, compared with children without $\mathrm{AD}$, suffering $\mathrm{AD}$ was significantly associated with higher risks of experiencing ADHD (OR = 1.563; 95\% CI, 1.382-1.769; $Z=7.095, p<0.001)$; sleep disorders (OR $=2.100$; 95\% CI, $1.322-$ $3.336 ; Z=3.144, p<0.01)$; anxiety $(\mathrm{OR}=1.339$; $95 \% \mathrm{CI}, 1.062-$ $1.687 ; Z=2.471, p<0.05)$; depression $(\mathrm{OR}=1.402 ; 95 \% \mathrm{CI}$, $1.256-1.565 ; Z=6.012, p<0.001)$; conduct disorder $(\mathrm{OR}=1.494$; $95 \%$ CI, $1.230-1.815 ; Z=4.049, p<0.001)$; and ASD $(\mathrm{OR}=2.574$; 95\% CI, 1.469-4.510; $Z=3.305, p<0.01$ ) (see Supplementary Appendix 2). There was no statistically significant difference in risk of suffering any of these mental disorders $\left(Q_{b}=8.344\right.$, $p=0.138$ ) in children with AD. Effect sizes for affective disorder, eating disorder, and ODD were not significant, and effect sizes for attachment disorder, PDD, personality disorder, speech disorder, and tic disorders are not presented, as there was only one study which reported on each of these outcomes.

\section{Publication Bias}

Visual inspection of the funnel plot (see Supplementary Appendix 3) and the findings of the Egger test indicated no significant publication bias $(t=1.020, p=0.315)$. The unbiased effect size $(\mathrm{OR}=1.500 ; 95 \% \mathrm{CI}, 1.329$ to 1.694) was marginally smaller than the calculated effect size $(\mathrm{OR}=1.652)$. The classic fail-safe number 


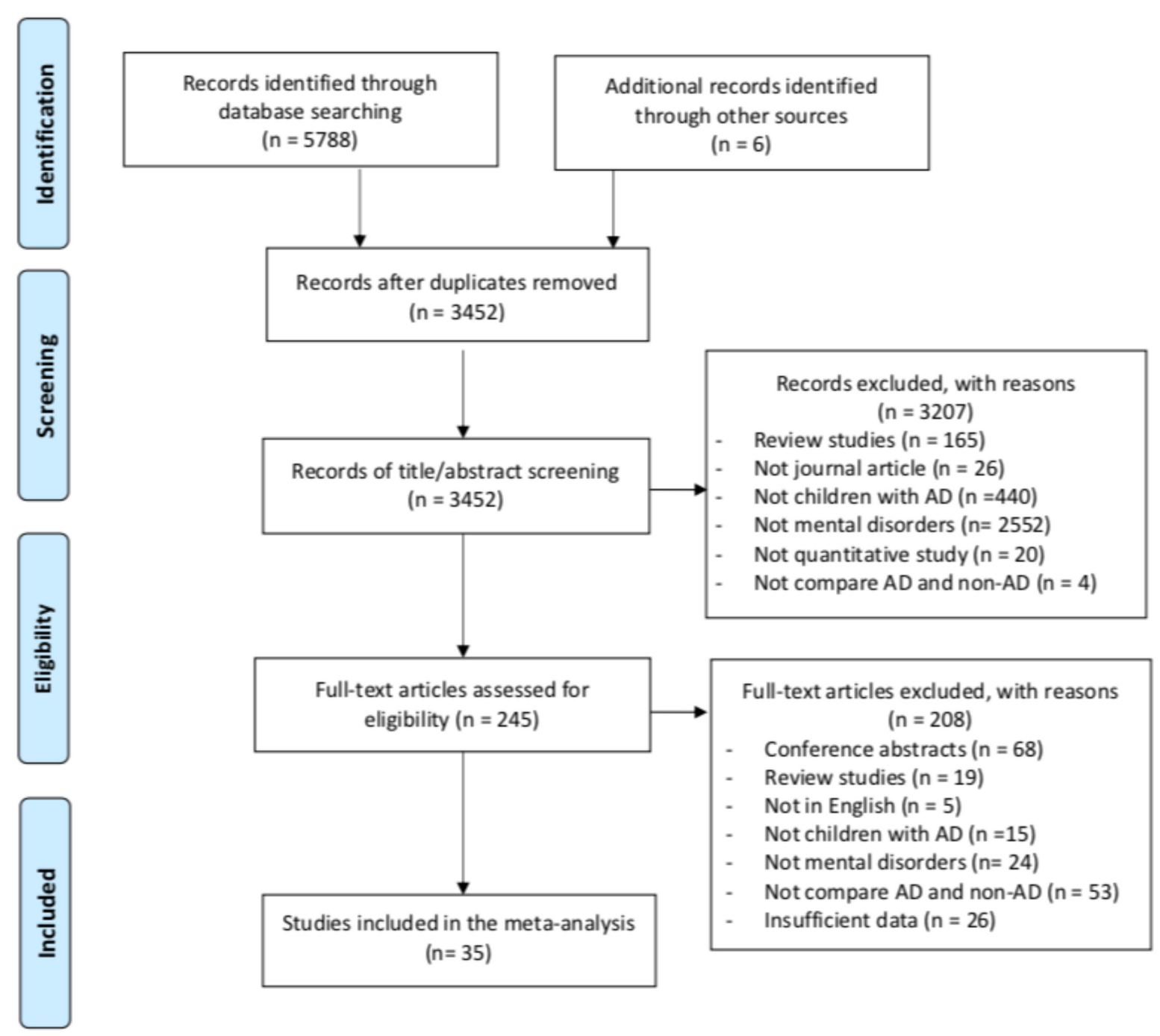

FIGURE 1 | Selection of articles for inclusion.

indicated that 4,591 studies with null findings needed to be added to negatively impact (overturn) the overall-effect $p$-value.

\section{Moderators of Risks of Mental Disorders in Children With AD}

Total sample size $\left(Q_{b}=6.687, p=0.083\right)$ and year of publication $\left(Q_{\mathrm{b}}=2.336, p=0.126\right)$ did not significantly contribute to between-group variance. Table 4 presents the analysis of potential categorical moderators.

For demographic factors, race/ethnicity was a significant moderator (Predominantly minority race $>$ Predominantly Caucasian; $\left.Q_{\mathrm{b}}=4.963, p=0.026\right)$. However, mean age $\left(Q_{\mathrm{b}}=2.626, p=0.269\right)$ and gender $\left(Q_{\mathrm{b}}=0.099, p=0.753\right) \mathrm{did}$ not significantly contribute to between-group variance.

For socioeconomic factors, family SES $\left(Q_{b}=0.418, p=0.518\right)$, HDI $\left(Q_{\mathrm{b}}=1.974, p=0.160\right)$, and GNI per capital $\left(Q_{\mathrm{b}}=2.188\right.$, $p=0.139)$ did not significantly contribute to betweengroup variance.

For methodological factors, the comparator group (healthy control group $>$ people with other conditions $>$ general population; $\left.Q_{b}=32.464, p=0.000\right)$, type of study $\left(Q_{b}=19.464\right.$, $p=0.000$; case control studies $>$ cohort studies $>$ cross-sectional studies), and representativeness of the sample (convenience or clinical samples $>$ randomly selected or community samples; $Q_{b}=6.359, p=0.012$ ) contributed significantly to betweengroup variance. Also, assessment of $\mathrm{AD}$ (diagnosed by a doctor or health professional $>$ self/parental report of doctoral diagnosis $>$ questionnaire; $Q_{b}=8.089, p=0.018$ ) and raters of mental disorders (parents or caregivers $>$ clinicians $>$ selfreported; $\left.Q_{\mathrm{b}}=10.600, p=0.005\right)$ contributed significantly to between-group variance. However, equivalence of patients and control group $\left(Q_{\mathrm{b}}=3.255, p=0.071\right)$ and quality of studies $\left(Q_{\mathrm{b}}=2.507, p=0.113\right)$ were not statistically significant as moderators. 
TABLE 2 | Characteristics of participants and studies.

\begin{tabular}{|c|c|c|c|c|c|c|c|c|c|c|c|c|c|c|}
\hline Study name & A & B & C & D & $\mathbf{E}$ & $\mathbf{F}$ & G & $\mathbf{H}$ & $\mathbf{I}$ & J & $\mathbf{K}$ & $\mathbf{L}$ & $\mathbf{M}$ & $\mathbf{N}$ \\
\hline Absolon et al., 1997 & $30 / 30$ & 9.3 & $5-15$ & 51.7 & 53.5 & $47.0 / 10.0$ & 21.5 & United Kingdom* & 2 & 1 & 3 & 1 & 1 & 6 \\
\hline Augustin et al., 2015 & $30354 / 263827$ & NR & $0-18$ & 48.8 & NR & NR & NR & Germany* & 3 & 2 & 3 & 2 & 1 & 6 \\
\hline Beyreiss et al., 1988 & $81 / 81$ & NR & $5-12$ & NR & NR & NR & NR & $N R$ & 2 & $N R$ & $N R$ & 1 & NR & 3 \\
\hline Brew et al., 2018 & $3152 / 11045$ & 9.0 & 9 & 49.6 & NR & NR & NR & Sweden* & 1 & 2 & 2 & 2 & 3 & 6 \\
\hline Buske-Kirschbaum et al., 1997 & $15 / 15$ & 11.9 & $9-14$ & 53.3 & NR & NR & NR & Germany* & 2 & 1 & 1 & 1 & 1 & 7 \\
\hline Camfferman et al., 2010 & $77 / 30$ & 9.9 & $6-16$ & 50.2 & NR & NR & NR & Australia* & 2 & 1 & 1 & 1 & 1 & 6 \\
\hline Catal et al., 2016 & $80 / 74$ & 2.1 & $3-$ & 48.6 & NR & NR & 28.6 & Turkey & 2 & 1 & 2 & 1 & 1 & 3 \\
\hline Chang et al., 2013 & $84 / 473$ & 4.8 & $3-7$ & 48.7 & $\mathrm{NR}$ & NR & 40.7 & Korea* & 3 & 2 & 2 & 2 & 3 & 7 \\
\hline Chun et al., 2015 & $325 / 2867$ & 15.1 & $10-18$ & 43.4 & 100 & NR & 16.9 & Korea* & 3 & 2 & 2 & 2 & 2 & 8 \\
\hline Covaciu et al., 2013 & $508 / 2648$ & 8.0 & 8 & 49.7 & NR & NR & NR & Sweden* & 1 & 2 & 2 & 2 & 1 & 7 \\
\hline Genuneit et al., 2014 & $200 / 570$ & 11.0 & 11 & 50.1 & NR & NR & NR & Germany* & 1 & 2 & 2 & 2 & 1 & 8 \\
\hline Horev et al., 2017 & $840 / 900$ & 10.2 & $2-18$ & 49.2 & NR & NR & 43.5 & Israel* & 2 & 1 & 3 & 1 & 1 & 7 \\
\hline Johansson et al., 2017 & $1178 / 2428$ & NR & $10-18$ & 49.4 & NR & NR & 16.4 & Sweden* & 1 & 2 & 2 & 2 & 2 & 9 \\
\hline Khandaker et al., 2014 & $994 / 5121$ & 12.9 & 13 & 53.2 & 2.0 & $N R$ & NR & United Kingdom* & 1 & 2 & 2 & 1 & 2 & 7 \\
\hline Kuniyoshi et al., 2018 & $1641 / 8313$ & NR & $7-14$ & 50.0 & 100 & NR & NR & Japan* & 3 & 2 & 2 & 2 & 3 & 7 \\
\hline Lee et al., 2016 & $18473 / 18473$ & NR & $3-13$ & 46.2 & 100 & $38.3 / 17.1$ & NR & Taiwan* & 2 & 2 & 3 & 1 & 1 & 9 \\
\hline Lee and Shin, 2017 & $4904 / 67531$ & NR & $12-17$ & 53.0 & 100 & NR & 10.9 & Korea* & 3 & 2 & 2 & 1 & 2 & 8 \\
\hline Liao et al., 2016 & $387262 / 387262$ & NR & $6-10$ & 47.4 & 100 & NR & 30.3 & Taiwan* & 1 & 2 & 3 & 1 & 1 & 9 \\
\hline Lien et al., 2010 & $1030 / 2320$ & NR & $15-16$ & 56.7 & NR & NR & 2.4 & Norway* & 3 & 1 & 2 & 2 & 3 & 7 \\
\hline Romanos et al., 2010 & $1952 / 11366$ & 9.9 & $3-17$ & 50.4 & NR & $12.6 / 3.9$ & 25.6 & Germany* & 3 & 2 & 2 & 2 & 2 & 8 \\
\hline Sarkar et al., 2004 & $22 / 20$ & 4.8 & $3-9$ & 40.5 & NR & NR & NR & India & 2 & 1 & 1 & 1 & 1 & 6 \\
\hline Schmitt et al., 2009 & $1436 / 1436$ & 12.6 & $6-17$ & 59.9 & $N R$ & $10.3 / 2.9$ & NR & Germany* & 2 & 2 & 3 & 1 & 1 & 7 \\
\hline Schmitt et al., 2010a & $780 / 2136$ & 10.0 & 10 & 49.0 & NR & $12 / 5$ & 8 & Germany* & 1 & 2 & 2 & 2 & 1 & 7 \\
\hline Schmitt et al., 2011 & $367 / 1162$ & 10.0 & 10 & 48.5 & NR & $11 / 4$ & 14 & Germany* & 1 & 2 & 2 & 1 & 2 & 8 \\
\hline Schmitt et al., 2018 & $42 / 47$ & 9.9 & $6-12$ & 36.5 & NR & NR & 11.4 & Germany* & 3 & 1 & 1 & 2 & 1 & 5 \\
\hline Shani-Adir et al., 2009 & $57 / 37$ & 7.0 & $4-10$ & 50.8 & NR & NR & NR & |srael* & 2 & 1 & 1 & 2 & 1 & 4 \\
\hline Shyu et al., 2012 & 10620/178093 & NR & $0-17$ & 47.8 & 100 & NR & NR & Taiwan* & 1 & 2 & 3 & 2 & 1 & 9 \\
\hline Silverberg and Simpson, 2013 & $10333 / 69334$ & 8.0 & $0-17$ & 49.1 & 45.2 & $25.1 / 12.3$ & 17.9 & United States* & 3 & 2 & 2 & 2 & 2 & 7 \\
\hline Slattery and Essex, 2011 & $48 / 197$ & 13.0 & 13 & 34.7 & 11 & NR & NR & United States* & 1 & 2 & 3 & 2 & 3 & 7 \\
\hline Strom and Silverberg, 2016 & $33808 / 302955$ & NR & $2-17$ & NR & NR & NR & NR & United States* & 1 & 2 & 2 & 2 & 2 & 7 \\
\hline Afsar et al., 2010 & $36 / 36$ & 11.6 & $9-16$ & 41.7 & NR & NR & NR & Turkey & 2 & 1 & 2 & 1 & 1 & 5 \\
\hline Urrutia-Pereira et al., 2017 & $340 / 454$ & 6.8 & $4-10$ & NR & 100 & NR & NR & \# & 2 & 1 & 1 & 1 & 1 & 7 \\
\hline Wang et al., 2017 & $95 / 434$ & 2.0 & $1-2$ & 48.9 & $\mathrm{NR}$ & NR & 27.3 & China & 3 & 1 & 3 & 1 & 1 & 7 \\
\hline Yaghmaie et al., 2013 & $10401 / 69095$ & NR & $0-18$ & 48.6 & 44.5 & 25.2/NR & 18.1 & United States* & 3 & 2 & 2 & 2 & 2 & 7 \\
\hline Yang et al., 2018 & $411 / 2361$ & NR & $3-6$ & 46.6 & 100 & NR & 32 & Taiwan* & 3 & 2 & 2 & 2 & 2 & 7 \\
\hline
\end{tabular}

(A), sample size: numbers of participants in AD group/Non-AD group; $(B)$, age of child (mean): mean age (years) of participated children in total sample; (C), age of child (range): range of age of participated children in total sample; $(D)$, sex of child: percentage of females in total sample; $(E)$, race/ethnicity of child: percentage of racial or ethnic minorities in total sample; (F), asthma: Percentage of children who were identified as having asthma by the included study in AD group/Non-AD group; (G), home socioeconomic status (SES): percentage of families which were defined as low SES by the included study in total sample; (H), location: country or territory in which the study was conducted; (I), type of study: 1 = cohort, 2 = case-control, 3 = cross sectional; $(\mathrm{J})$, representativeness of the sample: $1=$ convenience sample or clinical sample, 2 = random sample or community sample; $(K)$, target of comparison: nature of the Non-AD group, 1 = healthy control, $2=$ general population, $3=$ people with other conditions; (L), equivalence: equivalence of $A D$ group and Non-AD group, 1 = yes, 2 = no; $(M)$, assessment of $A D$ : method employed to identify $A D$ of participants; 1, diagnosed by a doctor or professional; 2, self/parental report of doctoral diagnosis; 3, questionnaire; $(\boldsymbol{N})$, assessment of quality: total score calculated according to the Newcastle-Ottawa Quality Assessment Forms; NR, not report; \#Nine countries in Latin America including Argentina, Brazil, Colombia, Cuba, Dominican Republic, Honduras, Mexico, Paraguay, and Uruguay; *developed countries or territories defined as those possessing an Human Development Index [HDI] over 0.800 according to United Nations Development Programme [UNDP] (2018).

\section{DISCUSSION}

Skin as the largest organ of our body constitutes the boundaries between internal and external environments (Suárez et al., 2012). Besides biological symptoms, children with $\mathrm{AD}$ are more likely to encounter psychological challenges than their healthy peers. This meta-analysis of 35 studies $(n=1,935,147$ children/adolescents) found that $\mathrm{AD}$ could result in higher risk of mental disorders among children and adolescents by providing conclusive evidence that children with $\mathrm{AD}$ were, on average, $65.2 \%$ more likely to develop mental disorders, compared with children without $\mathrm{AD}$.

Previous studies have attempted to explore the mechanisms in which how AD impacts the psychological well-being of children. First, symptoms and characteristics of $\mathrm{AD}$, such as severe and constant pruritus, chronic and relapsing nature, chronic inflammation, and high risk of atopic or allergic comorbidity may directly explain the elevated risk of mental disorders 
TABLE 3 | Outcomes and measurements.

\begin{tabular}{|c|c|c|c|c|}
\hline Study name & Outcome domains & Measurement of outcome & $\begin{array}{l}\text { Rater of } \\
\text { outcomes }\end{array}$ & Original metric \\
\hline Absolon et al., 1997 & Psychological disturbance (including sleep disturbance) & Rutter A2 scale & Clinician & Rates or events \\
\hline Augustin et al., 2015 & ADHD, depression & Diagnosed & Clinician & OR \\
\hline Beyreiss et al., 1988 & ADHD & Parents Rating Scale & Parent/caregiver & Rates or events \\
\hline Brew et al., 2018) & Anxiety/depression & SCARED, SMFQ & Parent/caregiver & OR \\
\hline Buske-Kirschbaum et al., 1997 & Anxiety & Anxiety Inventory for Children & Child/adolescent & OR \\
\hline Camfferman et al., 2010 & ADHD, sleep disorder & $\begin{array}{l}\text { SDSC, Conners Parent Rating } \\
\text { Scale-Revised }\end{array}$ & Parent/caregiver & Mean and SD \\
\hline Catal et al., 2016 & $\begin{array}{l}\text { Psychiatric disorders (including ADHD, anxiety, attachment } \\
\text { disorder, conduct disorder, eating disorder, ODD, sleep } \\
\text { disorders, and tic disorders) }\end{array}$ & $\mathrm{ECl}-4$ & Parent/caregiver & Rates or events \\
\hline Chang et al., 2013 & $\begin{array}{l}\text { ADHD, affective disorder, anxiety, externalizing problem, } \\
\text { internalizing problem, ODD, PDD, and sleep disorders }\end{array}$ & CBCL & Parent/caregiver & Mean and SD \\
\hline Chun et al., 2015 & Depression & Self-designed questionnaire & Parent/caregiver & Rates or events \\
\hline Covaciu et al., 2013 & Anxiety/depression & Subscale of EQ-5D & Parent/caregiver & Rates or events \\
\hline Genuneit et al., 2014 & ADHD & Diagnosed & Clinician & Rates or events \\
\hline Horev et al., 2017 & ADHD & Diagnosed & Clinician & OR \\
\hline Johansson et al., 2017 & ADHD & Diagnosed & Clinician & OR \\
\hline Khandaker et al., 2014 & Psychotic experiences & PLIKSi & Child/adolescent & OR \\
\hline Kuniyoshi et al., 2018 & $\begin{array}{l}\text { Mental health problems (including ADHD, and conduct } \\
\text { disorder) }\end{array}$ & $\mathrm{SDQ}$ & Parent/caregiver & OR \\
\hline Lee et al., 2016 & ADHD, ASD & Diagnosed & Clinician & Rates or events \\
\hline Lee and Shin, 2017 & Depression & Self-designed questionnaire & Child/adolescent & Rates or events \\
\hline Liao et al., 2016 & ADHD, ASD & Diagnosed & Clinician & Rates or events \\
\hline Lien et al., 2010 & Internalizing and externalizing mental health problems & HSCL-10, SDQ & Child/adolescent & OR \\
\hline Romanos et al., 2010 & ADHD & Diagnosed & Clinician & OR \\
\hline Sarkar et al., 2004 & $\begin{array}{l}\text { Psychological disorders (including anxiety, conduct } \\
\text { disorder, depression) }\end{array}$ & CPMS & Parent/caregiver & Mean and SD \\
\hline Schmitt et al., 2009 & $\begin{array}{l}\text { ADHD, affective disorder, eating disorder, personality } \\
\text { disorder }\end{array}$ & Diagnosed & Clinician & Rates or events \\
\hline Schmitt et al., 2010a & $\begin{array}{l}\text { Mental health problems (including ADHD, and conduct } \\
\text { disorder) }\end{array}$ & $\mathrm{SDQ}$ & Parent/caregiver & OR \\
\hline Schmitt et al., 2011 & $\begin{array}{l}\text { Mental health problems (including ADHD, and conduct } \\
\text { disorder) }\end{array}$ & $\mathrm{SDQ}$ & Parent/caregiver & OR \\
\hline Schmitt et al., 2018 & $\begin{array}{l}\text { ADHD, mental health problems (including } \\
\text { anxiety/depression), and sleep disorders }\end{array}$ & $\begin{array}{l}\text { Conners } 3 \text { Rating Scales, } \\
\text { CBCL, CSHQ, SSR }\end{array}$ & $\begin{array}{l}\text { Child/adolescent } \\
\text { and } \\
\text { parent/caregiver }\end{array}$ & Mean and SD \\
\hline Shani-Adir et al., 2009 & Sleep disorders & $\mathrm{CSHQ}$ & Parent/caregiver & OR \\
\hline Shyu et al., 2012 & ADHD & Diagnosed & Clinician & OR \\
\hline Silverberg and Simpson, 2013 & Sleep disorders & Self-designed questionnaire & Parent/caregiver & Rates or events \\
\hline Slattery and Essex, 2011 & Anxiety, depression & $\mathrm{HBQ}, \mathrm{OCHS}$ & $\begin{array}{l}\text { Child/adolescent } \\
\text { and } \\
\text { parent/caregiver }\end{array}$ & Mean and SD \\
\hline Strom and Silverberg, 2016 & Speech disorder & Diagnosed & Clinician & Rates or events \\
\hline Afsar et al., 2010 & Anxiety & STAI-C & Child/adolescent & Mean and SD \\
\hline Urrutia-Pereira et al., 2017 & Sleep disorders & $\mathrm{CSHQ}$ & Parent/caregiver & Mean and SD \\
\hline Wang et al., 2017 & Sleep disorders & $\mathrm{BISQ}$ & Parent/caregiver & OR \\
\hline Yaghmaie et al., 2013 & ADHD, anxiety, ASD, conduct disorder, depression & Diagnosed & Clinician & Rates or events \\
\hline Yang et al., 2018 & ADHD & Diagnosed & Clinician & OR \\
\hline
\end{tabular}

ADHD, attention-deficit/hyperactivity disorder; ASD, autism spectrum disorder; BISQ, Brief Infant Sleep Questionnaire; CBCL, Child Behavior Checklist; CPMS, Childhood Psychopathology Measurement Schedule questionnaire; CSHQ, Children's Sleep Habits Questionnaire; Diagnosed, diagnosed by a doctor or professional; ECI-4, Early Childhood Inventory-4; HBQ, Health and Behavior Questionnaire (parental assessed); HSCL-10, The ten-item version of Hopkins Symptoms Checklist; OCHS, The Ontario Child Health Study scale (self-assessed by child); ODD, oppositional defiant disorder; PDD, pervasive developmental disorder, PLIKSi, Psychosis-like Symptoms interview; SCARED, Child Anxiety Related Emotional Disorders; SDSC, Sleep Disturbance Scale for Children; SMFQ, Shorted Mood and Feelings; SSR, Sleep Self Report (self-assessed by child); STAI-C, State-Trait Anxiety Inventory for Children; OR, odds ratio; SD, standard deviation. 


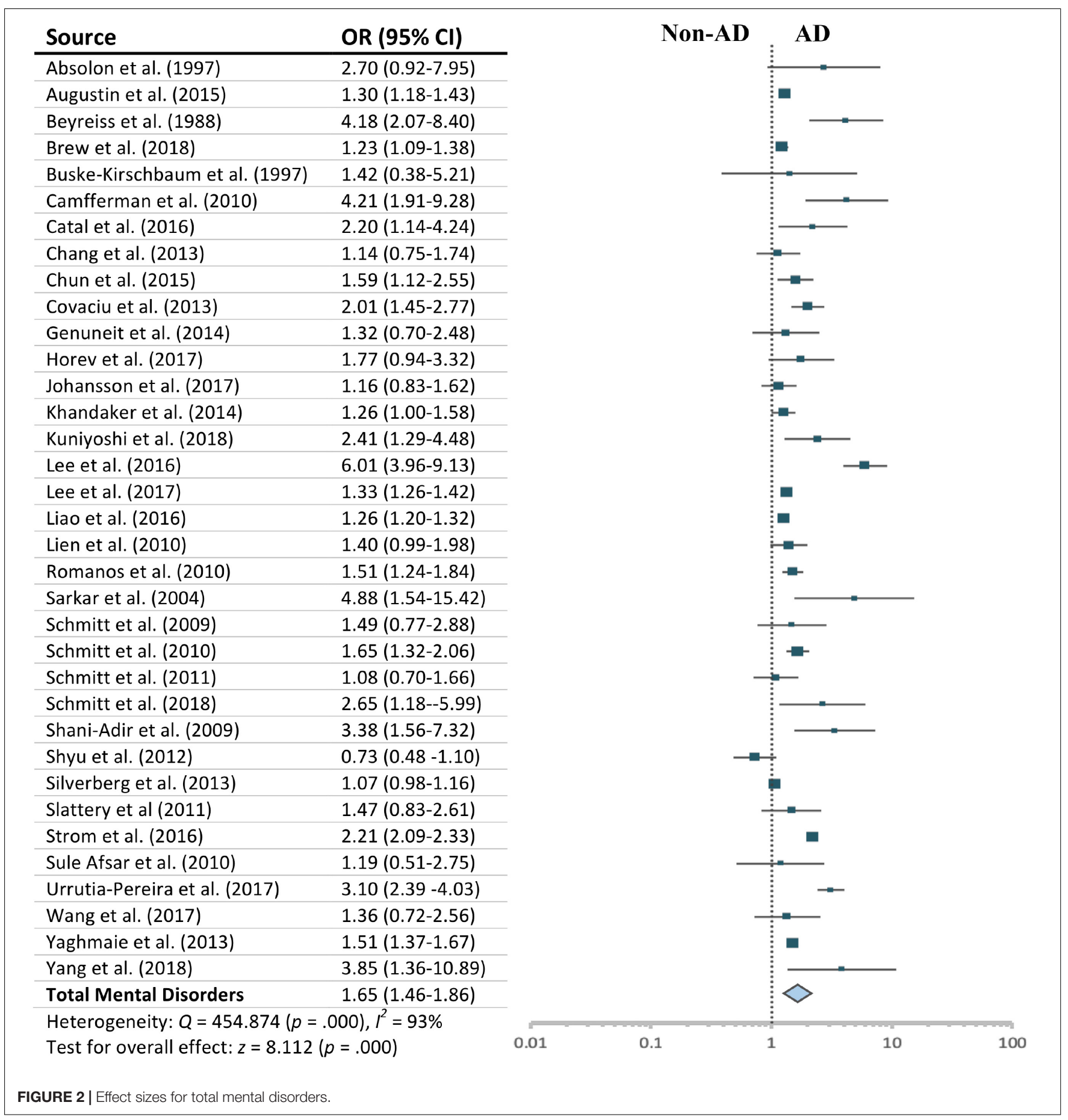

in children with AD (Silverberg and Simpson, 2013; Horev et al., 2017). Sleep disorders caused by pruritus may further strengthen the impact of AD on mental health of sufferers (Shyu et al., 2012). Pediatric AD may also indirectly induce mental disorders through dysfunctional social relationships (Bronkhorst et al., 2016; Chernyshov, 2016). In fact, recent studies have suggested that the relationships between suffering AD and mental disorders could be reciprocal (Chang et al., 2013; Becker-Haimes et al., 2017). Mental disorders may cause, induce, or exacerbate the physical symptoms of $\mathrm{AD}$ through decreased tolerance of pruritus, pain, and disfigurement; and lower adherence to medical treatment (Bronkhorst et al., 2016). Mental disorders can further cause adverse outcomes such as educational and career impairments, and increased risk for suicide in children with AD (Chun et al., 2015; Lee and Shin, 2017).

Topical therapies for treating physical symptoms are commonly the first line in the management of pediatric $\mathrm{AD}$ (Stein and Cifu, 2016). The high risk of mental disorders in 
TABLE 4 | Moderator variables analysis.

\begin{tabular}{|c|c|c|c|c|c|}
\hline \multirow[t]{2}{*}{ Moderators } & \multirow[t]{2}{*}{$k$} & \multirow{2}{*}{$\begin{array}{c}\text { Random Effect Size } \\
\text { OR }(95 \% \mathrm{Cl})\end{array}$} & \multicolumn{3}{|c|}{ Heterogeneity } \\
\hline & & & $Q_{w}$ & $p$ & $I^{2}$ \\
\hline Sample size & & & $Q_{b}=6.687$ & 0.083 & \\
\hline Less than 100 & 6 & $2.419(1.605,3.647)$ & 5.637 & 0.343 & 11.306 \\
\hline $100-1000$ & 8 & $2.046(1.397,2.997)$ & 28.467 & 0.000 & 75.410 \\
\hline 1001-10000 & 11 & $1.518(1.308,1.761)$ & 16.572 & 0.084 & 39.656 \\
\hline More than 10000 & 10 & $1.477(1.228,1.777)$ & 374.917 & 0.000 & 97.599 \\
\hline Year of publication & & & $Q_{b}=2.336$ & 0.126 & \\
\hline Earlier than or in 2010 & 11 & $1.944(1.532-2.468)$ & 21.936 & 0.015 & 54.413 \\
\hline Later than 2010 & 24 & $1.568(1.365-1.802)$ & 427.818 & 0.000 & 94.624 \\
\hline Mean age & & & $Q_{b}=2.626$ & 0.269 & \\
\hline $0-6$ years & 6 & $1.829(1.118,2.993)$ & 29.474 & 0.000 & 83.036 \\
\hline $7-11$ years & 11 & $1.641(1.347,1.999)$ & 53.168 & 0.000 & 81.192 \\
\hline $12-18$ years & 6 & $1.364(1.151,1.616)$ & 1.430 & 0.921 & 0.000 \\
\hline Sex of child & & & $Q_{b}=0.099$ & 0.753 & \\
\hline Predominantly male ( > 50\%) & 20 & $1.488(1.316-1.681)$ & 120.600 & 0.000 & 84.245 \\
\hline Predominantly female ( > 50\%) & 11 & $1.536(1.314-1.794)$ & 19.937 & 0.030 & 49.843 \\
\hline Race/ethnicity of child & & & $Q_{b}=4.963$ & 0.026 & \\
\hline Predominantly Caucasian ( > 50\%) & 4 & $1.287(1.017-1.630)$ & 27.662 & 0.000 & 89.155 \\
\hline Predominantly minority ( > 50\%) & 9 & $1.872(1.487-2.355)$ & 112.859 & 0.000 & 92.912 \\
\hline Family SES & & & $Q_{b}=0.418$ & 0.518 & \\
\hline More than $20 \%$ low SES families & 8 & $1.458(1.220,1.743)$ & 13.279 & 0.066 & 47.286 \\
\hline Less than $20 \%$ low SES families & 9 & $1.356(1.192,1.543)$ & 40.365 & 0.000 & 80181 \\
\hline HDI in 2018 & & & $Q_{b}=1.974$ & 0.160 & \\
\hline Developed countries or territories & 29 & $1.559(1.376,1.768)$ & 408.119 & 0.000 & 93.139 \\
\hline Developing countries or territories & 5 & $2.190(1.387-3.457)$ & 10.518 & 0.033 & 61.971 \\
\hline GNI per capital in 2017 & & & $Q_{b}=2.188$ & 0.139 & \\
\hline High income countries & 25 & $1.528(1.333,1.752)$ & 306.686 & 0.000 & 92.174 \\
\hline Middle or low income countries & 5 & $2.190(1.387,3.457)$ & 10.518 & 0.033 & 61.971 \\
\hline Type of study & & & $Q_{b}=19.464$ & 0.000 & \\
\hline Cohort & 11 & $1.362(1.088-1.704)$ & 262.520 & 0.000 & 96.191 \\
\hline Case-control & 12 & $2.809(2.081-3.790)$ & 26.845 & 0.005 & 59.024 \\
\hline Cross-sectional & 12 & $1.386(1.242-1.547)$ & 45.166 & 0.000 & 75.645 \\
\hline Target of comparison & & & $Q_{b}=32.464$ & 0.000 & \\
\hline Health control & 6 & $3.144(2.525-3.195)$ & 2.736 & 0.741 & 0.000 \\
\hline General population & 19 & $1.477(1.256-1.725)$ & 286.948 & 0.000 & 93.727 \\
\hline People with other conditions & 9 & $1.565(1.239-1.977)$ & 63.657 & 0.000 & 87.433 \\
\hline Representativeness of the sample & & & $Q_{b}=6.359$ & 0.012 & \\
\hline Convenience sample/clinical sample & 12 & $2.211(1.671-2.925)$ & 24.159 & 0.012 & 54.469 \\
\hline Random sample/community sample & 22 & $1.483(1.297-1.696)$ & 392.730 & 0.000 & 94.653 \\
\hline Equivalence of patients and control group & & & $Q_{b}=3.255$ & 0.071 & \\
\hline Yes & 16 & $1.903(1.548-2.287)$ & 124.684 & 0.000 & 87.970 \\
\hline No & 19 & $1.511(1.274-1.792)$ & 284.734 & 0.000 & 93.678 \\
\hline Assessment of AD & & & $Q_{b}=8.089$ & 0.018 & \\
\hline Diagnosed by a doctor or professional & 19 & $1.904(1.562-2.322)$ & 139.674 & 0.000 & 87.113 \\
\hline Self/parental report of doctoral diagnosis & 10 & $1.439(1.161-1.784)$ & 262.994 & 0.000 & 96.578 \\
\hline Questionnaire & 5 & $1.318(1.118-1.553)$ & 5.145 & 0.273 & 22.257 \\
\hline Rater of mental disorders & & & $Q_{b}=10.600$ & 0.005 & \\
\hline Child/adolescent & 5 & $1.331(1.257-1.409)$ & 0.384 & 0.984 & 0.000 \\
\hline Parent/caregiver & 15 & $1.849(1.481-2.308)$ & $114.477^{* * *}$ & 0.000 & 87.770 \\
\hline Clinician & 13 & $1.632(1.321-2.018)$ & $296.077^{* * *}$ & 0.000 & 95.947 \\
\hline Assessment of Quality & & & $Q_{b}=2.507$ & 0.113 & \\
\hline High methodological quality & 25 & $1.484(1.445-1.525)$ & 410.627 & 0.000 & 94.614 \\
\hline Moderate methodological quality & 10 & $1.339(1.245-1.441)$ & 37.554 & 0.000 & 76.034 \\
\hline
\end{tabular}

$k=$ number of studies; 95\% Cl= lower and upper limits if 95\% confidence interval; Qw/Qb = test for homogeneity of effect sizes within (w) and between (b) groups. 
children with $\mathrm{AD}$, and the resultant negative consequences make it clear that successful management of pediatric AD requires a multipronged approach including psychological input, rather than just the medical treatments of physical symptoms (Ersser et al., 2014). Indeed, there has been growing interest in integrative medicine (IM) to manage pediatric $\mathrm{AD}$ in healthcare settings (Bodeker et al., 2017). This approach addresses healing of the whole person, including both physical, psychological, and social dimensions (Bell et al., 2002; McClafferty et al., 2017). There would also seem to be a strong indication that working with the psychological dimensions of children should be an integral and routine part of the management of AD (Bronkhorst et al., 2016). Mental health care adjunctive to medical treatments has great potential to help children with $\mathrm{AD}$ to manage itching and scratching, increase adherence to skin-directed care, develop coping competencies, accept their disease and themselves emotionally, and improve quality of life (Ersser et al., 2014). Addressing emotional distress of children with $\mathrm{AD}$ may be an important key to break the vicious cycle of $\mathrm{AD}$ and mental disorders in children.

The findings of this review suggest the need for greater inclusion of effective mental health care into holistic management of $\mathrm{AD}$ and the importance of multidisciplinary cooperation. On the one hand, health care professionals including dermatologists, allergists, pediatricians, and primary care physicians require a greater understanding of the risk of mental disorders in children with AD (Lee et al., 2016). When treating children with severe $\mathrm{AD}$, screening procedures for identifying mental disorders should be emphasized in conjunction with medical treatment (Cheng et al., 2015). On another hand, mental health professionals including psychiatrists, psychologists, and social workers should give further attention to the symptoms of $\mathrm{AD}$ when treating mental disorders of children and adolescents, and also provide effective mental health care to children with AD. Additionally strategies such as listing and recommending mental health care in treatment or management guidelines of pediatric $\mathrm{AD}$ and increasing insurance coverage of mental health care for children in health care system should be considered.

Moreover, this study has significant implications for future practice and research. First, this study provided stronger evidence to point toward positive associations between pediatric $\mathrm{AD}$ and different types of mental disorders, such as ASD (OR = 2.574); sleep disorders $(\mathrm{OR}=2.100)$; $\mathrm{ADHD}(\mathrm{OR}=1.563)$, conduct disorder $(\mathrm{OR}=1.494)$, depression $(\mathrm{OR}=1.402)$, and anxiety $(\mathrm{OR}=1.339)$. The impacts of pediatric $\mathrm{AD}$ on different mental disorders were not shown to be significantly different. We suggest that psychological treatments need to target specific mental disorders of children with $\mathrm{AD}$ by using different techniques, rather than providing ubiquitous treatment, or just focusing on ADHD. Second, this study found that social-demographic factors including age, gender, and family/country SES did not moderate the impact of $\mathrm{AD}$ on mental disorders of sufferers. Mental health care should be developed for, and accessed by, young children and adolescents of both genders, from all family SES, and in both developed countries and developing countries. Third, more research focus is required on NonCaucasian children since studies on children from minority races predominantly yielded larger effect size than those with predominantly Caucasian children. Fourth, this study found that studies with parents or caregivers as raters of mental disorders yielded larger effect size than those with clinicians or children themselves as raters. Providing daily care to a child with AD usually imposes a heavy psychological burden on parents due to the complex and long-term treatment management (Mitchell et al., 2015). The psychological stress of parents might exaggerate the degree of severity of children's mental disorders in their reports. Only using parents or caregivers as the child's proxy to report on the child's health may induce bias. There is a need to involve the voices of children in future research and practice for moving closer to the best care appropriate for children.

\section{Limitations}

First, a broad range of outcome measures was included to calculate the overall effect size of Total Mental Disorders. This resulted in large heterogeneity. We addressed this by conducting independent meta-analyses to assess the effect sizes related to specific mental disorders, and we also employed a more discriminatory random-effects model. Second, gray literature was not included in this meta-analysis. Due to our strict inclusion criteria, we were able to include only a limited number of studies. There were insufficient numbers of studies to support separate meta-analyses for some mental disorders, such as attachment disorders, personality disorders, and tic disorders. Third, the way we assessed for moderator impacts was exploratory, and the results should be interpreted with caution. We could not test for a number of important moderator variables, including medical factors (e.g., severity of $\mathrm{AD}$, onset age and duration of $\mathrm{AD}$, medical treatments received), immunologic factors (e.g., serum immunoglobulin [IgE] levels), genetic factors (e.g., family history of $\mathrm{AD}$ ), and social factors (e.g., social relationships) because too few studies provided this information. More research on these important variables is needed for further investigating the mechanisms that how $\mathrm{AD}$ and mental disorders might be interrelated, which would be crucial for improved treatment of both disorders. Additionally, few studies provided information regarding the severity of mental disorders. Future research should explore the association between pediatric $\mathrm{AD}$ and different degrees of mental disorders, as not all children may require the same level of support.

\section{CONCLUSION}

$\mathrm{AD}$ is a disease resulting in significant somatic suffering and psychological disturbance. This meta-analysis identified that children and adolescents with $\mathrm{AD}$ had higher risk of mental disorders compared to those without $\mathrm{AD}$. This review highlighted the importance of integrated, holistic, multidisciplinary management of pediatric $\mathrm{AD}$, which emphasizes the well-being of the whole person. 


\section{AUTHOR CONTRIBUTIONS}

Q-WX conceptualized and designed the study, searched and screened the studies, extracted and analyzed the data, assessed quality of studies, wrote the initial draft of the manuscript, and significantly contributed to revision. XD screened the studies, extracted the data, assessed quality of the studies, and revised the manuscript. XT screened the studies. CLWC and CHYC critically reviewed and revised the manuscript, and significantly improved the manuscript

\section{REFERENCES}

Absolon, C., Cottrell, D., Eldridge, S., and Glover, M. (1997). Psychological disturbance in atopic eczema: the extent of the problem in school-aged children. Br. J. Dermatol. 137, 241-245. doi: 10.1046/j.1365-2133.1997.18121896.x

Afsar, F., Isleten, F., and Sonmez, N. (2010). Children with atopic dermatitis do not have more anxiety or different cortisol levels compared with normal children. J. Cutan. Med. Surg. 14, 13-18. doi: 10.2310/7750.2010.09021

American Psychiatric Association (2013). Diagnostic and Statistical Manual of Mental Disorders, 5th Edn. Washington, DC: American Psychiatric Association.

Archer, C. (2013). Atopic eczema. Medicine 41, 341-344. doi: 10.1016/j.mpmed. 2013.04.002

Augustin, M., Radtke, M., Glaeske, G., Reich, K., Christophers, E., Schaefer, I., et al. (2015). Epidemiology and comorbidity in children with psoriasis and atopic eczema. Dermatology 231, 35-40. doi: 10.1159/000381913

Becker-Haimes, E., Diaz, K., Haimes, B., and Ehrenreich-May, J. (2017). Anxiety and atopic disease: comorbidity in a youth mental health setting. Child Psychiatr. Hum. Dev. 48, 528-536. doi: 10.1007/s10578-016-0678-8

Bell, I., Caspi, O., Schwartz, G., Grant, K., Gaudet, T., Rychener, D., et al. (2002). Integrative medicine and systemic outcomes research. Arch. Intern. Med. 162, 131-132. doi: 10.1001/archinte.162.2.133

Beyreiss, J., Roth, N., Beyer, H., Kropf, S., Shlenzka, K., Schmidt, A., et al. (1988). Coincidence of immune (atopic dermatitis) and behavioral (attention deficit) disorders in children: empirical data. Act. Nerv. Super. 30, 127-128.

Bodeker, G., Ryan, T., Volk, A., Harris, J., and Burford, G. (2017). Integrative skin care: dermatology and traditional and complementary medicine. J. Altern. Complement. Med. 23, 479-486. doi: 10.1089/acm.2016.0405

Borenstein, M., Hedges, L. V., Higgins, J. P. T., and Rothstein, H. R. (2009). Introduction to Meta-Analysis. West Sussex, UK: John Wiley \& Sons Ltd.

Brew, B., Lundholm, C., Gong, T., Larsson, H., and Almqvist, C. (2018). The familial aggregation of atopic diseases and depression or anxiety in children. Clin. Exp Allergy 48, 703-711. doi: 10.1111/cea.13127

Bronkhorst, E., Schellack, N., and Motswaledi, M. (2016). Effects of childhood atopic eczema on the quality of life: review article. Curr. Allergy Clin. Immunol. $29,18-22$.

Bui, A., Dieleman, J., Hamavid, H., Birger, M., Chapin, A., Duber, H., et al. (2017). Spending on children's personal health care in the United States, 1996-2013. JAMA Pediatr. 171, 181-189. doi: 10.1001/jamapediatrics.2016.4086

Buske-Kirschbaum, A., Jobst, S., Wustmans, A., Kirschbaum, C., Rauh, W., and Hellhammer, D. (1997). Attenuated free cortisol response to psychosocial stress in children with atopic dermatitis. Psychosom. Med. 59, 419-426. doi: 10.1097/ 00006842-199707000-00012

Camfferman, D., Kennedy, J. D., Gold, M., Martin, A. J., Winwood, P., and Lushington, K. (2010). Eczema, sleep, and behavior in children. J. Clin. Sleep Med. 6, 581-588.

Carson, C. G. (2013). Risk factors for developing atopic dermatitis. Dan. Med. J. 60:B4687.

Catal, F., Topal, E., Soylu, N., Ozel Ozcan, O., Celiksoy, M., Babayiðit, A., et al. (2016). Psychiatric disorders and symptoms severity in preschool children with atopic eczema. Allergol. Immunopathol. 44, 120-124. doi: 10.1016/j.aller.2015. 04.006

Chang, H., Seo, J., Kim, H., Kwon, J., Kim, B., Kim, H., et al. (2013). Allergic diseases in preschoolers are associated with psychological and quality. All authors approved the final version of the manuscript as submitted and agreed to be accountable for all aspects of the work.

\section{SUPPLEMENTARY MATERIAL}

The Supplementary Material for this article can be found online at: https://www.frontiersin.org/articles/10.3389/fpsyg. 2019.01773/full\#supplementary-material

behavioural problems. Allergy Asthma Immunol. Res. 5, 315-321. doi: 10.4168/aair.2013.5.5.315

Cheng, C., Hsu, J., Huang, K., Bai, Y., Su, T., Li, C., et al. (2015). Risk of developing major depressive disorder and anxiety disorders among adolescents and adults with atopic dermatitis: a nationwide longitudinal study. J. Affect. Disord. 178, 60-65. doi: 10.1016/j.jad.2015.02.025

Chernyshov, P. V. (2016). Stigmatization and self-perception in children with atopic dermatitis. Clin. Cosmet. investig. Dermatol. 9, 159-166. doi: 10.2147/ ccid.s91263

Chida, Y., Hamer, M., and Steptoe, A. (2008). A bidirectional relationship between psychosocial factors and atopic disorders: a systematic review and metaanalysis. Psychosom. Med. 70, 102-116. doi: 10.1097/psy.0b013e31815c1b71

Chun, Y., Han, K., Park, Y., Yoon, J., Kim, H., Kim, J., et al. (2015). Examining impacts of allergic diseases on psychological problems and tobacco use in korean adolescents: the 2008-2011 korean national health and nutrition examination survey. PLoS One 10:e125172. doi: 10.1371/journal. pone. 0125172

Covaciu, C., Bergström, A., Lind, T., Svartengren, M., and Kull, I. (2013). Childhood allergies affect health-related quality of life. J. Asthma 50, 522-528. doi: 10.3109/02770903.2013.789057

Dertlioglu, S. B., Didar Balci, D., Cicek, D., and Halisdemir, N. (2012). Dermato logy life quality index in children with vitiligo. Eur. J. Pediatr. Dermatol. 22, 81-82.

Ersser, S., Cowdell, F., Latter, S., Gardiner, E., Flohr, C., Thompson, A., et al. (2014). Psychological and educational interventions for atopic eczema in children. Cochrane Database Syst. Rev. 7:CD004054. doi: 10.1002/14651858.cd004054. pub3

Genuneit, J., Braig, S., Brandt, S., Wabitsch, M., Florath, I., Brenner, H., et al. (2014). Infant atopic eczema and subsequent attention-deficit/hyperactivity disorder-a prospective birth cohort study. Pediatr. Allergy Immunol. 25, 51-56. doi: $10.1111 /$ pai. 12152

Herzog, R., Álvarez-Pasquin, M., Díaz, C., Del Barrio, J., Estrada, J., and Gil, Á (2013). Are healthcare workers' intentions to vaccinate related to their knowledge, beliefs and attitudes? a systematic review. BMC Public Health 13:15. doi: 10.1186/1471-2458-13-154

Horev, A., Freud, T., Manor, I., Cohen, A. D., and Zvulunov, A. (2017). Risk of attention-deficit/hyperactivity disorder in children with atopic dermatitis. Acta Dermatovenerol. Croat. 25, 210-214.

Johansson, E., Ballardini, N., Kull, I., Bergström, A., and Wahlgren, C. (2017). Association between preschool eczema and medication for attentiondeficit/hyperactivity disorder in school age. Pediatr. Allergy Immunol. 28, 44-50. doi: 10.1111/pai.12657

Khandaker, G., Zammit, S., Lewis, G., and Jones, P. (2014). A population-based study of atopic disorders and infl ammatory markers in childhood before adolescent psychotic experiences. Early Interv. Psychiatry 8:58. doi: 10.1016/j. schres.2013.09.021

Kuniyoshi, Y., Kikuya, M., Miyashita, M., Yamanaka, C., Ishikuro, M., Obara, T., et al. (2018). Severity of eczema and mental health problems in Japanese schoolchildren: the tommo child health study. Allergol. Intern. 67, 481-486. doi: 10.1016/j.alit.2018.02.009

Lee, C., Chen, M., Jeng, M., Hsu, J., Tsai, S., Bai, Y., et al. (2016). Longitudinal association between early atopic dermatitis and subsequent attention-deficit or autistic disorder. Medicine 95:e5005. doi: 10.1097/md.0000000000005005 
Lee, S., and Shin, A. (2017). Association of atopic dermatitis with depressive symptoms and suicidal behaviors among adolescents in Korea: the 2013 korean youth risk behavior survey. BMC Psychiatr. 17:3. doi: 10.1186/s12888-0161160-7

Liao, T., Lien, Y., Wang, S., Huang, S., and Chen, C. (2016). Comorbidity of atopic disorders with autism spectrum disorder and attention deficit/hyperactivity disorder. J. Pediatr. 171, 248-255. doi: 10.1016/j.jpeds.2015.12.063

Lien, L., Green, K., Thoresen, M., and Bjertness, E. (2010). Atopic conditions and mental health problems: a 3-year follow-up study. Eur. Child Adolesc. Psychiatr. 19, 705-713. doi: 10.1007/s00787-010-0106-8

Lipsey, M., and Wilson, D. (2001). Practical Meta-Analysis. Thousand Oaks, CA: Sage.

McClafferty, H., Vohra, S., Bailey, M., Brown, M., Esparham, A., Gerstbacher, D., et al. (2017). Pediatric integrative medicine. Pediatrics 140:e20171961. doi: 10.1542/peds.2017-1961

McInnes, M., Moher, D., Thombs, B., McGrath, T., Bossuyt, P., Clifford, T., et al. (2018). Preferred reporting items for a systematic review and meta-analysis of diagnostic test accuracy studies. JAMA 319, 388-396. doi: 10.1001/jama.2017. 19163

Mercer, M., Joubert, G., Ehrlich, R., Nelson, H., Poyser, M., Puterman, A., et al. (2004). Socioeconomic status and prevalence of allergic rhinitis and atopic eczema symptoms in young adolescents. Pediatr. Allergy Immunol. 15, 234-241. doi: 10.1111/j.1399-3038.2004.00125.x

Mitchell, A., Fraser, J., Ramsbotham, J., Morawska, A., and Yates, P. (2015). Childhood atopic dermatitis: a cross-sectional study of relationships between child and parent factors, atopic dermatitis management, and disease severity. Intern. J. Nurs. Stud. 52, 216-228. doi: 10.1016/j.ijnurstu.2014.09.008

Nygaard, U., Riis, J., Deleuran, M., and Vestergaard, C. (2016). Attentiondeficit/hyperactivity disorder in atopic dermatitis: an appraisal of the current literature. Pediatri. Allergy Immunol. Pulmonol. 29, 181-188. doi: 10.1089/ped. 2016.0705

Riis, J., Vestergaard, C., Deleuran, M., and Olsen, M. (2016). Childhood atopic dermatitis and risk of attention deficit/hyperactivity disorder: a cohort study. J. Allergy Clin. Immunol. 138, 608-610. doi: 10.1016/j.jaci.2016.01.027

Romanos, M., Gerlach, M., Warnke, A., and Schmitt, J. (2010). Association of attention-deficit/hyperactivity disorder and atopic eczema modified by sleep disturbance in a large population-based sample. J. Epidemiol. Commun. Health 64, 269-273. doi: 10.1136/jech.2009.093534

Rønnstad, A. T. M., Halling-Overgaard, A. A., Hamann, C. R., Skov, L., Egeberg, A., and Thyssen, J. P. (2018). Association of atopic dermatitis with depression, anxiety, and suicidal ideation in children and adults: a systematic review and meta-analysis. J. Am. Acad. Dermatol. 79, 448-456. doi: 10.1016/j.jaad.2018.03.017

Sarkar, R., Raj, L., Kaur, H., Basu, S., Kanwar, A., and Jain, R. (2004). Psychological disturbances in indian children with atopic eczema. J. Dermatol. 31, 448-454. doi: 10.1111/j.1346-8138.2004.tb00530.x

Schans, J., Çiçek, R., de Vries, T., Hak, E., and Hoekstra, P. (2017). Association of atopic diseases and attention-deficit/hyperactivity disorder: a systematic review and meta-analyses. Neurosci. Biobehav. Rev. 74, 139-148. doi: 10.1016/j. neubiorev.2017.01.011

Schmitt, J., Apfelbacher, C., Chen, C., Romanos, M., Sausenthaler, S., Koletzko, S., et al. (2010a). Infant-onset eczema in relation to mental health problems at age 10 years: results from a prospective birth cohort study (german infant nutrition intervention plus). J. Allergy Clin. Immunol. 125, 404-410. doi: 10.1016/j.jaci. 2009.10.055

Schmitt, J., Buske-Kirschbaum, A., and Roessner, V. (2010b). Is atopic disease a risk factor for attention-deficit/hyperactivity disorder? Syst. Rev. Allergy 65, 1506-1524. doi: 10.1111/j.1398-9995.2010.02449.x

Schmitt, J., Buske-Kirschbaum, A., Tesch, F., Trikojat, K., Stephan, V., Abraham, S., et al. (2018). Increased attention-deficit/hyperactivity symptoms in atopic dermatitis are associated with history of antihistamine use. Allergy 73, 615-626. doi: 10.1111/all.13326

Schmitt, J., Chen, C., Apfelbacher, C., Romanos, M., Lehmann, I., Herbarth, O., et al. (2011). Infant eczema, infant sleeping problems, and mental health at 10 years of age: the prospective birth cohort study LISAplus. Allergy 66, 404-411. doi: 10.1111/j.1398-9995.2010.02487.x

Schmitt, J., Romanos, M., Schmitt, N. M., Meurer, M., and Kirch, W. (2009). Atopic eczema and attention-deficit/hyperactivity disorder in a populationbased sample of children and adolescents. JAMA 301, 724-726. doi: 10.1001/ jama.2009.136
Shani-Adir, A., Rozenman, D., Kessel, A., and Engel-Yeger, B. (2009). The relationship between sensory hypersensitivity and sleep quality of children with atopic dermatitis. Pediatr. Dermatol. 26, 143-149. doi: 10.1111/j.1525-1470. 2009.00904.x

Shyu, C., Lin, H., Lin, C., and Fu, L. (2012). Prevalence of attentiondeficit/hyperactivity disorder in patients with pediatric allergic disorders: a nationwide, population-based study. J. Microbiol. Immunol. Infect. 45, 237-242. doi: 10.1016/j.jmii.2011.11.008

Silverberg, J., and Paller, A. (2015). Association between eczema and stature in 9 US population-based studies. JAMA Dermatol. 151, 401-409. doi: 10.1001/ jamadermatol.2014.3432

Silverberg, J., and Simpson, E. (2013). Association between severe eczema in children and multiple comorbid conditions and increased healthcare utilization. Pediatr. Allergy Immunol. 24, 476-486. doi: 10.1111/pai.12095

Slattery, M., and Essex, M. (2011). Specificity in the association of anxiety, depression, and atopic disorders in a community sample of adolescents. J. Psychiatr. Res. 45, 788-795. doi: 10.1016/j.jpsychires.2010.11.003

Stein, S. L., and Cifu, A. S. (2016). Management of atopic dermatitis. JAMA 315, 1510-1511. doi: 10.1001/jama.2016.1459

Sterne, J., Egger, M., and Smith, G. (2001). SInvestigating and dealing with publication and other biases in meta-analysis. BMJ 323, 101-105. doi: 10.1136/ bmj.323.7304.101

Stewart, A., Mitchell, E., Pearce, N., Strachan, D., and Weiland, S. (2001). The relationship of per capita gross national product to the prevalence of symptoms of asthma and other atopic diseases in children (ISAAC). Intern. J. Epidemiol. 30, 173-179. doi: 10.1093/ije/30.1.173

Strom, M., and Silverberg, J. (2016). Eczema is associated with childhood speech disorder: a retrospective analysis from the national survey of children's health and the national health interview survey. J. Pediatr. 168, 185-192. doi: 10.1016/ j.jpeds.2015.09.066

Suárez, A., Steinhoff, M., Feramisco, J., and Koo, J. (2012). Psychoneuroimmunology of psychological stress and atopic dermatitis: pathophysiologic and therapeutic updates. Acta Derm. Venereol. 92, 7-15. doi: 10.2340/00015555-1188

United Nations Development Programme [UNDP]. (2018). Human Development Reports, Human Development Data. Available at: http://hdr.undp.org/en/data (accessed July 24, 2019).

Urrutia-Pereira, M., Solé, D., Rosario, N., Neto, H., Acosta, V., Almendarez, C., et al. (2017). Sleep-related disorders in latin-american children with atopic dermatitis: a case control study. Allergol. Immunopathol. 45, 276-282. doi: 10.1016/j.aller.2016.08.014

Wang, X., Gao, X., Yang, Q., Wang, X., Li, S., Jiang, F., et al. (2017). Sleep disorders and allergic diseases in chinese toddlers. Sleep Med. 37, 174-179. doi: 10.1016/j. sleep.2017.02.011

Wells, G., Shea, B., O'connell, D., Petersen, J., Welch, V., Losos, M., et al. (2012). The Newcastle-Ottawa Scale (NOS) for Assessing the Quality of Nonrandomized Studies in Meta-Analyses. Ottawa, ON: University of Ottawa.

Xie, Q. W., and Tang, X. (2018). Mental Disorders of Children with Eczema: A Systematic Review and Meta-Analysis. PROSPERO 2018 CRD42018087957. Available at: https://www.crd.york.ac.uk/PROSPERO/ (accessed July 24, 2019).

Yaghmaie, P., Koudelka, C. W., and Simpson, E. L. (2013). Mental health comorbidity in patients with atopic dermatitis. J. Allergy Clin. Immunol. 131, 428-433. doi: 10.1016/j.jaci.2012.10.041

Yang, C., Yang, C., and Wang, I. (2018). Association between allergic diseases, allergic sensitization and attention-deficit/hyperactivity disorder in children: a large-scale, population-based study. J. Chin. Med. Assoc. 81, 277-283. doi: 10.1016/j.jcma.2017.07.016

Conflict of Interest Statement: The authors declare that the research was conducted in the absence of any commercial or financial relationships that could be construed as a potential conflict of interest.

Copyright ( 2019 Xie, Dai, Tang, Chan and Chan. This is an open-access article distributed under the terms of the Creative Commons Attribution License (CC BY). The use, distribution or reproduction in other forums is permitted, provided the original author(s) and the copyright owner(s) are credited and that the original publication in this journal is cited, in accordance with accepted academic practice. No use, distribution or reproduction is permitted which does not comply with these terms. 